Journal of Animal and Veterinary Advances 11 (11): 1864-1867, 2012

ISSN: $1680-5593$

(C) Medwell Journals, 2012

\title{
Comparative Proteomic Studies on Serum of Brucellosis Dairy Cows and Health Dairy Cows
}

\author{
${ }^{1}$ Jinzhong Tao, ${ }^{1}$ Yansheng Guo, ${ }^{2}$ Lihong Feng, ${ }^{5}$ Guoshun Zhao, ${ }^{3}$ Qianming Wu, \\ ${ }^{4}$ Xuewen Yang, ${ }^{2}$ Shuxia Kuai, ${ }^{1}$ Shunde Liu and ${ }^{6} \mathrm{~J}$ ianfeng Wang \\ ${ }^{1}$ College of Agriculture, Ningxia University, 750021 Yingchuan, P.R. China \\ ${ }^{2}$ Ningxia Center for Disease Control and Prevention, \\ ${ }^{3}$ The Town of Bian dan gou Veterinary Station, \\ ${ }^{4}$ The Township of Ma lian qu Veterinary Station, 751100 Wuzhong, P.R. China \\ ${ }^{5}$ College of Veterinary Medicine, Gansu Agricultural University, 730070 Lanzhou, P.R. China \\ ${ }^{6}$ Lanzhou Institute of Biological Products, 730046 Lanzhou, P.R. China
}

\begin{abstract}
In order to provide an evidence of brucellosis for diagnosis and prevention, 2D-electrophoresis and SDS-PAGE were applied to detect protein expression difference in plasma between healthy dairy cows and dairy cows suffered from Brucellosis. The results showed that 11 differentially protein spots were found by PDQUest 8.0 Software and 5 of them were detected by ion trap mass spectrum. Apoprotein C-III and Serum Amyloid protein A (SAA) were acute phase protein and lipometabolism-related proteins which can serves as the plasma biomarkers of brucellosis-associated proteins for diagnosis and prevention.
\end{abstract}

Key words: Dairy cows, brucellosis, proteomic, 2-DE, MS, plasma, biomarkers

\section{INTRODUCTION}

Brucellosis, infected by Brucella species bacteria is a highly contagious and allergic zoonosis which is characterized by reproductive organs and fetal membranes inflammation resuting in not only domestic animal abortion, premature delivery, infertility, placental retention, orchitis, arthritis, never injury and local disease focus in various tissue but also human undulant fever, endocarditis, arthritis and medullitis.

Milk cow inflected Brucellosis often manifest abortion, dystocia, fetus mummy and even milk yiled drop. Furthermore, Brucellosis posed the serious threat to china dairy industry due to rapid spread.

However, the reseraches mainly focus on the antigen and antibody detection and molecular epidemiology of brucellosis dairy cows up to the present with the coming of the post genomic era, the rapid developing proteomics technology provide a new method for studying the marker of the disease molecular diagnosis.

This investigation was to detect the expressed proteins in plasma from Brucellosis dairy cows by the proteomics approach in order to find plasma biomarkers of brucellosis-associated proteins for diagnosis and treatment.

\section{MATERIALS AND METHODS}

Material and equipment: UV-1800 ultraviolet spectrophotometer was purchased from Shimadzu (Japan). The instrument for the Protean IEF Cell System and the PROTEAN II xi 2DE Cells System were purchased from Bio-Rad laboratories (Hercules, CA, USA). The gels were scanned using a GS-800 scnner (Amersham pharmacia Biotech, Uppsala, Sweden) and image analysis was carried out using PDQUest 8.0 image analysis software (Bio-Rad, Hercules, CA, USA) non-linear immobilized $\mathrm{pH}$ gradient $(3-10 \mathrm{NL}, 17 \mathrm{~cm})$, non-linear immobilized $\mathrm{pH}$ gradient (4-7NL, $17 \mathrm{~cm}$ ), IPG Buffer $\mathrm{pH}$ 3 10, 2-D cleanup kit, mineral oil, acryla-mide, methylene bis-acrylamide were purchased from Bio-Rad laboratories (Hercules, CA, USA) 3-3 (Cholamidolpropyl) Dimethylammonio-1 -Propane Sulfonate (CHAPS), glycine, urea, thiocarbamate, Dithiothreitol (DTT), N, N, N, N'Tetramethyle-thylenediamine (TEMED), low melting-point agarose, ammonium persulfate, iodoace-tamide, Coomassie brilliant blue G-250, Sodium Dodecyl Sulfate (SDS), Bovine Serum Albumin (BSA) were phchased from Sigma Chemical (St. Louis, MO, USA), Brucellosis plate antigen were obtained from the Qingdao Yebio Bio-Engineering Co., Ltd. Album and IgG Depletion SpintrapTM were obtained from GE, all other chemicals were of analytical reagent grade.

Corresponding Author: Shunde Liu, College of Agriculture, Ningxia University, 750021 Yingchuan, P.R. China 
Samples collection: Biood samples were obtained from 40 clinical healthy dairy cows in a dairy farm in Ningxia province of China by jugular venipuncture and were anticoagulated with $0.5 \%$ EDTA. The blood samples were centrifuged. The plasma was collected and subpackaged in liquid nitrogen according to the positive or negative reaction that was detected by Plate Antigen Test (BPAT).

2-DE sample preparation: Positive and negative samples were taken out to mix equally and then quantitated by Bradford Method the mix samples were repacked and stored.

2-DE and SDS-PAGE: The plasma samples mixed with $350 \mu \mathrm{L}$ buffer solution (7M urea, $2 \mathrm{M}$ thiourea, 4\% CHAPS, $65 \mathrm{Mm}$ DTT, 0.2\% (w/v) Bio-Lyte and trace bromophenol blue) were centrifuged at $12000 \times \mathrm{g}$ for $5 \mathrm{~min}$ at $4^{\circ} \mathrm{C}$ and then were linearly added along the edge of a focusing tray from left to right. The cover sheet of IPG strips was taken out with forceps and its surface was adown placed in the IEF focusing tray after the anode and cathode of IPG strips were distinguished correctly. IPG strips were covered with $2 \sim 3 \mathrm{~mL}$ mineral oil. Samples were focused by following program (Firpo et al., 2009): $12 \mathrm{~h}$ at $50 \mathrm{~V}$ (initiative rehydration), $30 \mathrm{~min}$ at $250 \mathrm{~V}$ (linear), $1 \mathrm{~h}$ at $1000 \mathrm{~V}$ (fast), $5 \mathrm{~h}$ at $9000 \mathrm{~V}$ (linear) and focusing was continued at $9000 \mathrm{~V}$ to give a total of $68 \mathrm{kV} \mathrm{h}, 5 \mathrm{~h}$ at $250 \mathrm{~V}$ (fast) and arbitrarily time.

After the IEF, focused IPG strips were placed in reducing equilibration buffer that contained $6 \mathrm{M}$ urea, $2 \%$ SDS, 20\% glycerol, $50 \mathrm{Mm}$ Tris- $\mathrm{HCl}(\mathrm{pH} 8.8), 0.01 \%$ (w/v) bromophenol blue and $2 \%$ DTT for $15 \mathrm{~min}$ with shaking followed in alkylating equilibration buffer with $2.5 \%(\mathrm{w} / \mathrm{v})$ iodoacetamide instead of $2.0 \%$ DTT for an additional $15 \mathrm{~min}$, strips were then transferred and placed on a $12 \%$ $1 \mathrm{~mm}$ SDS-PAGE to carried out the second dimensional vertical electrophoresis until the bromophenol blue marker had reached the bottom of the gel.

Gel staining: Gels were fixed in $40 \%$ ethanol containing $10 \%$ acetic acid for at least $3 \mathrm{~h}$. Gels were then placed in a solution that containing $20 \%(\mathrm{v} / \mathrm{v})$ methanol, $10 \%(\mathrm{v} / \mathrm{v})$ phosphoric acid, $10 \%(\mathrm{v} / \mathrm{v})$ ammonium sulphate and $0.12 \%(\mathrm{w} / \mathrm{v})$ CBB G-250 for staining overnight and then were decolorized in $10 \%(\mathrm{v} / \mathrm{v})$ methanol with $5 \%(\mathrm{~m} / \mathrm{v})$ ammonium sulphate until background become clear (Reinders and Sickmann, 2009).

Image analysis and in gel digestion: The samples of experimental group and control group were repeated at least three times. Gel images were conducted to remove backgrounds and to automatically match protein points with PDQUest 8.0 Software, the data was statisticed with Excel 2003. Differentially expressed protein spots were excised manually using pipette tips. The gels particles were washed clearly with MilliQ water for $30 \mathrm{~min}$ and stored in $50 \%$ acetonitrile solution.

Protein identification and database search: The gel particles were decolorized with $50 \%$ acetonitrile and subjected to incubation containing sequence-grade trypsin at $37^{\circ} \mathrm{C}$ overnight for enzymolysis. The supernatant was transferred to a clean microtube. Peptide mass was determined on an iron trap tandom mass spectrometer (LCQ Deca Xp plus), MS/MS was performed in data-dependent mode. Peptides were indentified using SEQUEST of Bioworks Software to search against the publicly available NCBI nonredundant protein database from which the cattle data sublibrary was selected. The protein identification criteria were based on crosscorrelation score Xcorr (one charge $\geq 1.9$, two charges $\geq 2.2$, three charges $\geq 3.75$ ) .

Subsequently, the identified proteins were carried out the ultimate confirm after removing keratinose comtamination. And subsequently according to protein's FASTA format sequence text, the molecular weight and isoele-ctric point of each confirmed protein were numerated by using compute $\mathrm{pI} / \mathrm{Mw}$ (http://us.expasy. org/tools/pi_tool.html).

\section{RESULTS AND DISCUSSION}

Comparison of differential protein spots in 2-D gels: PDQUest 8.0 Software was used to remove backgrounds and to automatically match protein points. About 11 spots were detected as differential protein and shown in Fig. 1. Spot 1 and 2 were up-regulated proteins and Spot 3 was a down-regulated protein in healthy dairy cows while six spots (Spot 5, 6, 7, 9, 10 and 11) were up-regulated in Brucellosis dairy cows. Spot 4 was only expressed in health dairy cows while Spot 8 was only expressed in Brucellosis dairy cows.

Identification of differential protein spots by MS: All protein spots were analyzed by MS (Table 1) and 5 proteins were indentified as serum albumin precursor, apolipoprotein C-III, immunoglobulin heavy chain precursor, S06611Ig-2-chain $\mathrm{C}$ region and serum amyloid protein A. These proteins participate with tissue lipid metabolism and stress reaction. 


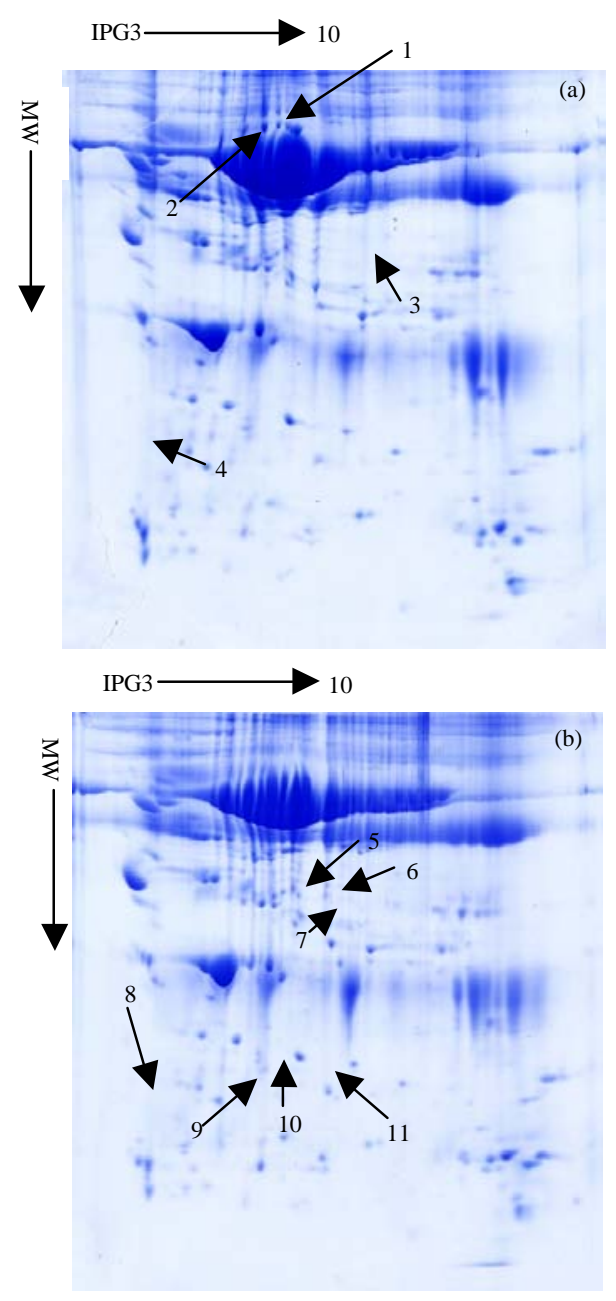

Fig. 1: 2-DE patterns of plasma from healthy dairy cows and Brucellosis dairy cows. a) 2-DE patterns from healthy cows and b) 2-DE patterns from Brucellosis dairy cows; arrows represent differential protein spot

Table 1: Identification of differential expression proteins by LC-MS/MS

\begin{tabular}{llc}
\hline Protein & Accession & $\mathrm{pI} / \mathrm{MW}$ \\
\hline Serum albumin precursor & NP_851335.1 & $5.82 / 69323.44$ \\
Serum albumin precursor & NP_851335.1 & $5.82 / 69323.44$ \\
Serum albumin precursor & NP_851335.1 & $5.82 / 69323.44$ \\
Apolipoprotein C-III & AAI11662.1 & $5.02 / 10692.13$ \\
S22080 Ig heavy chain precursor & S22080 & $6.10 / 50625.03$ \\
Serum albumin precursor & NP_851335.1 & $5.82 / 69323.44$ \\
Serum albumin precursor & NP_851335.1 & $5.82 / 69323.44$ \\
Apolipoprotein C-III & AAI11662.1 & $5.02 / 10692.13$ \\
S06611 Ig gamma-2 chain C region & S22080 & $6.10 / 50625.03$ \\
Serum amy loid A, SAA & AAB21386.1 & $6.94 / 12474.58$ \\
S06611 Ig gamma-2 chain C region & S22080 & $6.10 / 50625.03$ \\
\hline
\end{tabular}

Protein related to lipid metabolism change: Apolipoprotein is protein part of lipoprotein designated which is highly glycosylated (Gaubatz et al., 1983) and plays a important role in lipoprotein metabolism and physiologic function. Apolipotrotein has four main functions: structuring and steadying lipoprotein structure, modifying and regulating metabolism and activity of enzyme related to lipoprotein, severing as some enzymatic cofactor and severing as lipoprotein ligand responsible for deciding and participating the bind and metabolism of acceptor-associated lipoproteins or cell surface lipoproteins.

Rowell et al. (2012) reported that apolipotrotein C-III was a down-regulated one in human serum possibly resulting in chronic infection may be regarded as the potential molecular biomarker for serodiagnosis on $\mathrm{HCV}$ patient at present. Zhang et al. (2010) studied the change of serum protein on the patients suffered from transfevent prostatic cancer, 2-DE techniques was used to analyze the differentially expressed proteins. One protein was identified by MALDI-TOF-MS which was related to the formation and development of prostatic carcinoma, apolipoprotein C-III was a typical up-regulated protein. This provided an important clue for digonosis and treatment on invasion prostatic carcinoma. Liu et al. (2010) researched the changes of serum protein on patients suffered from medicamentous dermatitis, found that apolipotrotein C-III was a down-regulated one. This provided an evidence for explaining dermatitis pathologic mechanism and studying the diagnosis marker.

Serum Amyloid protein A (SAA), originated from liver, belongs to the apoprotein family of proteins. It is involved in a variety of physiological processes in human beings and animals. It connects to free haemoglobin released from erythrocytes to form haemoglobin-haptoglobin complexes and thereby inhibits haemoglobin oxidative activity and prevents hemolytic anemia within blood vessel. Generally, SAA is quickly secreted when an inflammation happens, transports cholesterol to liver and induces bile secretion, summons immunocyte to the inflammation part. In amyloidosis, like atherosclerosis, arthritis deformans etc. when amyloidosis (such as atherosclerosis, arthritis deformans and etc.) happens, the activity of SAA inducible enzyme reduce to relief the pathogenetic condition.

Ryan J Henderson (Firpo et al., 2009) reported that Haptoglobin (Hp) and SAA were up-regulated in pancreatic cancer patients, combining the acute phase proteins (Hp and SAA) level with cancer antigen 19-9 was higher diagnostic accuracy than use the cancer antigen 19-9 only. The change of blood protein in Cameroon fever patients was studied by Young Yil Bahk when the high abundance plasma proteins were removed and the differential protein spots were selected and detected by 2-DE electrophoresis and MS, respectively the results 
showed that Hp was down-regulated or even not detected in Cameroon fever patients blood while SAA was manifestly up-regulated. This means $\mathrm{Hp}$ and SAA can serve as the mark in clinical diagnosis for Cameroon fever in acute stage (Bahk et al., 2010). Hp also can serve as important biomolecule of detection and prognosis for of ovarial epithelial tumor in all stages (Zhao et al., 2007). Bovine serum SAA, Hp and IFN-1 were significantly increased at the early stage of O-FMDV hence, the three proteins can regarded as the biological tag of early FMDV diagnosis (Stenfeldt et al., 2011). Moreover, many acute phase proteins can serves as diagnostic marker for many animal diseases such as bovine respiratory syncytial virus, prostatic carcinoma, bronchopneumonia, Huppert's disease, mastitis and swine streptococcicosis, etc.

\section{CONCLUSION}

It was evidently change for plasma protein proteome in dairy cows suffered by brucellosis, apoprotein C-III and SAA were up-regulated in brucellosis dairy cows which can serves as the plasma biomarkers of brucellosisassociated proteins for diagnosis and prevention.

\section{ACKNOWLEDGEMENTS}

The project was supported by the National Natural Science Foundation of Ningxia province of China (NZ0902) and the National Natural Science Foundation of China (31160523). Jinzhong Tao and Yansheng Guo are both the first researchers of this study.

\section{REFERENCES}

Bahk, Y.Y., B.K. Na, S.H. Cho, J.Y. Kim, K.J. Lim and T.S. Kim, 2010. Proteomic analysis of haptoglobin and amyloid A protein levels in patients with vivax malaria. Korean J. Parasitol., 48: 203-211.
Firpo, M.A., D.Z. Gay, S.R. Granger, C.L. Scaife, J.A. DiSario, K.M. Boucher and S.J. Mulvihill, 2009. Improved diagnosis of pancreatic adenocarcinoma using haptoglobin and serum amyloid A in a panel screen. World J. Surg., 33: 716-722.

Gaubatz, J.W., C. Heideman, A.M. Gotto, J.D. Morrisett and G.H. Dahlen, 1983. Human plasma lipoprotein (a): Structural properties. J. Biol. Chem., 258: 4582-4589.

Liu, J.J., X.M. Xing, H.Y. Huang, J.H. Yuan and Y.Y. Xu et al., 2010. Screening and identification of differential serum proteins related to dermatitis medicamentosa-like of trichloroethylene. Zhonghua Yu Fang Yi Xue Za Zhi, 44: 485-489.

Reinders, J. and A. Sickmann, 2009. Proteomics. Humana Press, New Jersey, USA.

Rowell, J., A.J. Thompson, J.R. Guyton, X.Q. Lao, J.G. McHutchison, J.J. McCarthy and K. Patel, 2012. Serum apolipoprotein C-III is independently associated with chronic hepatitis $\mathrm{C}$ infection and advanced fibrosis. Hepatol. Int., 6: 475-481.

Stenfeldt, C., P.M. Heegaard, A. Stockmarr, K. Tjornehoj and G.J. Belsham, 2011. Analysis of the acute phase responses of Serum Amyloid A, Haptoglobin and Type 1 Interferon in cattle experimentally infected with foot-and-mouth disease virus serotype $O$. Vet. Res., Vol. 42. 10.1186/1297-9716-42-66

Zhang X.M., Y. Shen and Z.Q. Xianyu, 2010. Serum proteomic study of prostate cancer with bone metastasis. Zhonghua Nan Ke Xue, 16: 721-725.

Zhao, C., L. Annamalai, C. Guo, N. Kothandaraman and S.C. Koh et al., 2007. Circulating haptoglobin is an independent prognostic factor in the sera of patients with epithelial ovarian cancer. Neoplasia, 9: $1-7$. 